\title{
Response to: "Commentary on Delayed, two-staged autologous breast reconstruction: an approach to improving delayed reconstructive outcomes" by Mantelakis A, Kazzazi D, Bloom 0, Gallagher M, Weale R \& Geh J
}

\author{
Ashraf A. Patel ${ }^{1}$ - Lawrence Cai ${ }^{2} \cdot$ Shawn Moshrefi ${ }^{2} \cdot$ Ian C. Sando ${ }^{3} \cdot$ Gordon K. Lee $^{2} \cdot$ Rahim S. Nazerali $^{2}$
}

Received: 3 March 2021 / Accepted: 12 March 2021 / Published online: 25 March 2021

(C) The Author(s), under exclusive licence to Springer-Verlag GmbH Germany, part of Springer Nature 2021

Dear Sir,

We thank Mantelakis et al. [1] for their interest in our article "Delayed, two-staged autologous breast reconstruction: an approach to improving delayed reconstructive outcomes" [2]. The authors have provided a critical analysis that brings up excellent points for discussion. We have addressed the comments as follows:

1. Lee et al. [3] describes their prepectoral tissue expander placement immediately following mastectomy. Our technique differs in that we specifically describe prepectoral expander placement as a delayed reconstructive effort that occurs several months or years following mastectomy without any previous reconstructive efforts. Our study technique varies because we have a different patient population. Since reconstruction is occurring months to years after mastectomy, there remains the unique challenge of having the mastectomy skin flap being scarred down to the pectoralis muscle, which requires re-elevation of the flap and recreation of the breast pocket in which to place the expander.

2. The small number of patients who met inclusion criteria is due to this unique patient population. To have met inclusion criteria, the patient must have undergone delayed breast reconstruction without having had any prior breast

Rahim S. Nazerali

rnazerali@gmail.com

1 SUNY Upstate Medical University, Syracuse, NY, USA

2 Division of Plastic and Reconstructive Surgery, Stanford University Medical Center, 770 Welch Road, Suite 400, Palo Alto, CA 94304 , USA

3 Ascension Medical Group, Carmel, IN, USA reconstruction. Today, the vast majority of our patients have access to immediate reconstruction or forego reconstruction entirely; our population consisted of the small subgroup who initially did not have reconstruction and subsequently sought out reconstruction at a later time. This resulted in a small cohort of patients, and we excluded any expanders placed subpectorally which further narrowed our cohort.

3. This study did not intentionally exclude smokers, obese patients, or patients without any comorbidity, but it is important to note that a majority of the patients had received prior radiation which is a known risk factor for reconstructive complications [4]. An element of selection bias may have been present during initial surgical consultation, but for this study, comorbidities were not an exclusion factor.

4. All of our patients underwent mastectomy due to invasive ductal carcinoma (IDC). Since these reconstructions were delayed, we found that the mastectomy type was a more important factor for consideration in reconstruction (Table 1).

5. All patients in our group had undergone reconstruction with an abdominal free flap. The transverse rectus abdominis Muscle (TRAM) flap was used in 2 breasts, and the muscle-sparing TRAM flap was used in 6 breasts (Table 1). We offer all reconstructive options to our patients, and since this is a staged approach, many free flaps and the pedicled latissimus flap are available. This decision tends to be largely patient driven, and we have found abdominal free flaps to generally be more popular given the larger amount of tissue available.

6. Although the COVID-19 pandemic has had devastating consequences, we still believe that this reconstructive approach can lead to much improved long-term patient satisfaction and is an option that should be made available to 
Table 1 Pateint

demographics

\begin{tabular}{lll}
\hline $\begin{array}{l}\text { Breast cancer diagnosis } \\
\text { Invasive ductal carcinoma }\end{array}$ & 8 & $100 \%$ \\
$\begin{array}{l}\text { Mastectomy type } \\
\text { Nipple sparing }\end{array}$ & 2 & $25 \%$ \\
Skin sparing & 5 & $62.5 \%$ \\
Areolar sparing & 1 & $12.5 \%$ \\
Flap utilized & & \\
MS-TRAM & 6 & $75 \%$ \\
TRAM & 2 & $25 \%$ \\
\hline
\end{tabular}

the patient. The reconstructive procedure is two-staged: placement of the expander at stage 1 and reconstruction at stage 2. We do not consider mastectomy as a stage of reconstruction, and all of the patients in this series presented for delayed reconstruction several months or years after mastectomy, many of whom may have declined reconstruction initially but requested reconstruction at a later date. Our technique requires two procedures and vastly improves patient satisfaction and the soft-tissue envelope avoiding abdominal skin being placed on the chest, and it is imperative to consider the long-term advantages of this approach. By undergoing this additional surgery, patients could be less likely to undergo revisionary surgeries and have the stigmata of a delayed reconstruction, which can have several implicit and explicit costs. In the current public health climate, practitioners should take into consideration these short and long-term costs and benefits and effectively inform patients of their options after assessing disease burden, availability, and practicality of the hospital system.

7. Patient-reported outcomes (PROM) are an invaluable tool in assessing previously unmeasured benefits to certain reconstructive procedures. Although this is an area of research we are actively pursuing, PROMs are out of scope of the purpose of this case series, which was to (a) describe our reconstructive approach and (b) compare complication rates to those historically reported to ensure this approach does not increase complication rates.
We once again thank the authors for providing a commentary on our study. We find it imperative to understand this technique is indeed a two-staged reconstructive approach for patients seeking delayed breast reconstruction. To keep up with advances in breast cancer care, we further limited our reconstructions to only those done in the prepectoral plane. Though we hypothesize this greatly increases patient satisfaction, this remains an active further area of our research as we increase sample size and better understand patient satisfaction.

\section{Declarations}

Ethical approval Not applicable.

Informed consent Not applicable

Conflict of interest Ashraf A. Patel, Lawrence Cai, Shawn Moshrefi, Ian C. Sando, Gordon K. Lee, and Rahim S. Nazerali declare no competing interests.

\section{References}

1. Mantelakis A, Kazzazi D, Bloom O, Gallagher M, Weale R, Geh J (2021) Commentary on 'Delayed, two-staged autologous breast reconstruction: an approach to improving delayed reconstructive outcomes' by AA Patel, L Cai, S Moshrefi, IC Sando, GK Lee \& RS Nazerali. Eur J Plast Surg:1-2. https://doi.org/10.1007/s00238-02101795-4

2. Patel AA, Cai L, Moshrefi S, Sando IC, Lee GK, Nazerali RS (2020) Delayed, two-staged autologous breast reconstruction: an approach to improving delayed reconstructive outcomes. Eur J Plast Surg 43(5):563-568

3. Lee KR, Clavin N (2019) Bridging autologous reconstruction with pre-pectoral tissue expanders. Gland Surg 8(1):90-94

4. Chang EI, Liu TS, Festekjian JH, Da Lio AL, Crisera CA (2013) Effects of radiation therapy for breast cancer based on type of free flap reconstruction. Plast Reconstr Surg 131(1):1e-8e

Publisher's note Springer Nature remains neutral with regard to jurisdictional claims in published maps and institutional affiliations. 